Proceedings

\title{
Polycyclic Aromatic Hydrocarbons in Commercial Herbal Teas ${ }^{+}$
}

\author{
Edward Muntean ${ }^{1,2, *}$ and Nicoleta Muntean ${ }^{3}$ \\ 1 University of Agricultural Sciences and Veterinary Medicine Cluj Napoca, Romania \\ 2 Research \& Development Station for Agriculture, Turda, Romania \\ 3 Regional Center of Public Health Cluj Napoca, National Institute of Public Health, Romania; \\ n67muntean@yahoo.com \\ * Correspondence: edimuntean@yahoo.com; Tel.: +40-754-074375 \\ + Presented at the 1st International Electronic Conference on Plant Science, 1-15 December 2020; Available \\ online: https://iecps2020.sciforum.net/.
}

Published: 1 December 2020

\begin{abstract}
Contamination of herbal teas with polycyclic aromatic hydrocarbons (PAHs) can occur as a result of environmental pollution as well as during processing. This research fits into current concerns directed towards establishing the PAHs' contamination level of plant resources, the focus being on the priority PAHs as established by the US Environmental Protection Agency's and by the European Union. In this study, the PAHs' content of several commercial herbal teas brands was assessed by reversed-phase high performance liquid chromatography (HPLC) using an Agilent 1100 system with fluorescence and photodiode array detectors. The obtained data revealed that the maximum overall PAH's contamination in the studied herbal teas was recorded for dandelion, mulberry and St.John's wort, all of these exposing high surface area of leaves; from the 15 tracked PAHs, only three were present in all samples (acenaphthene, fluorene and benzo(b)fluoranthene), while anthracene and benzo(g,h,i)perylene were quantified in only two samples; the maximum levels of individual PAHs were recorded in dandelion.
\end{abstract}

Keywords: medicinal herbal teas; health risk; polycyclic aromatic hydrocarbons; contamination; HPLC

\section{Introduction}

The presence of polycyclic aromatic hydrocarbons (PAHs) in medicinal plants may result in health risk to consumers, which are generally hoping that a natural remedy may be helpful in the healing process. Contamination of herbal teas with PAHs can occur as a result of environmental pollution as well as during processing (e.g., in some drying or preservation stages that allow combustion products to come into contact with medicinal plants).

This research fits into current concerns directed towards establishing the PAHs' contamination level of plant resources, the focus being on the priority PAHs as established by the US Environmental Protection Agency's and by the European Union: benzo[a]-anthracene, benzo[b]fluoranthene, indeno[1,2,3-cd]pyrene, benzo[k]-fluoranthene, benzo[a]pyrene, dibenzo-[a,h]anthracene, naphthalene, acenaphthene, acenaphthylene, fluorene, phenanthrene, anthracene, fluoranthene, pyrene, chrysene and benzo(g,h,i)perylene.

The major research objective was the assessment of PAHs' content from several commercial herbal teas brands using high performance liquid chromatography (HPLC): basil (Basilici folium), chamomile (Chamomillae folium), mulberry (Mori folium), plantain (Plantaginis folium), dandelion (Taraxaci herba), mint (Menthae herba), St. John's wort (Hyperici herba), black locust (Acacia flos), common elder (Sambuci flos), lime (Tiliae flos), marigold (Calendula flos) and fennel (Foeniculi fructus). 


\section{Experiments}

Plant material: 12 herbal tea brands were purchased from local hypermarkets.

Extraction: $\sim 5 \mathrm{~g}$ tea samples were grounded, weighed then extracted with $20 \mathrm{~mL}$ hexane: acetone (1:1) for $30 \mathrm{~min}$ by ultrasonication, at room temperature ; the supernatant was decanted while the residue was re-extracted with a new volume of solvent mixture in the same conditions, the procedure being repeated twice more. The obtained extracts were combined, passed through an anhydrous $\mathrm{Na}_{2} \mathrm{SO}_{4}$ layer and evaporated to dryness in a rotary evaporator; the residue was dissolved in $2 \mathrm{~mL}$ acetonitrile, then the final solution was filtered through $0.47 \mathrm{~mm}$ PTFE membrane filter and injected in the HPLC system. Three replicates from each tea brand followed the same procedure.

HPLC analysis was accomplished using an Agilent 1100 system with fluorescence detection in which baseline separations for the above-mentioned PAHs were performed using an Envirosep PP column in a total run time less than $30 \mathrm{~min}$.

Data analysis: principal component analysis (PCA) and cluster analysis were completed on autoscaled data using Matlab (The Mathworks Inc., Natick, MA, USA).

\section{Results and Discussion}

The maximum overall PAH's contamination in the studied herbal teas was recorded for dandelion $(131.15 \mu \mathrm{g} / \mathrm{kg})$, mulberry $(27.78 \mu \mathrm{g} / \mathrm{kg})$ and St.John's wort $(18.28 \mu \mathrm{g} / \mathrm{kg})$, all of these exposing high surface area of leaves to environmental contamination with PAHs (Table 1).

From the 15 quantified PAHs, only three were present in all samples (acenaphthene, fluorene and benzo(b)fluoranthene), while anthracene and benzo(g,h,i)perylene were quantified in only two samples.

Table 1. Mean values of recorded PAHs' concentrations in the studied herbal teas $[\mathrm{mg} / \mathrm{kg}]$.

\begin{tabular}{|c|c|c|c|c|c|c|c|c|c|c|c|c|}
\hline & Basil & Fennel & Lime & Platain & Black locust & Chamomile & Mint & Marygold & Elder & St. John's wort & Mulberry & Dandelion \\
\hline Fluorene & 0.06 & 0.86 & 0.21 & 0.46 & 0.54 & 0.26 & 0.48 & 0.46 & 0.56 & 0.47 & 2.71 & 2.14 \\
\hline Phenanthrene & N.D. & N.D. & N.D. & N.D. & N.D. & 2.63 & N.D. & 2.21 & 3.43 & N.D. & 7.25 & 23.79 \\
\hline Fluoranthene & N.D. & N.D. & N.D. & N.D. & 0.55 & N.D. & N.D. & N.D. & 2.49 & 2.52 & 7.33 & 3.94 \\
\hline Pyrene & N.D. & N.D. & 1.30 & 0.85 & N.D. & N.D. & 0.27 & N.D. & 1.29 & N.D. & 0.13 & 28.91 \\
\hline Benz(a)anthracene & 0.13 & 0.32 & 0.11 & 0.13 & 0.21 & 0.22 & 0.28 & 4.98 & N.D. & 0.10 & 0.25 & N.D. \\
\hline Chrysene & 0.92 & 0.07 & 0.08 & N.D. & 2.40 & 3.34 & 2.04 & 0.59 & 0.04 & 0.22 & 1.51 & 1.16 \\
\hline Benzo(a)pyrene & N.D. & 0.03 & 0.03 & 0.19 & 0.06 & 0.04 & 0.06 & 0.14 & 0.10 & 0.14 & 0.11 & 8.89 \\
\hline $\operatorname{Dibenzo}(\mathrm{a}, \mathrm{h})$ anthracene & 0.13 & 0.05 & N.D. & 0.68 & 0.11 & N.D. & N.D. & 0.09 & 0.10 & 0.14 & N.D. & 0.15 \\
\hline Benzo $(g, h, i)$ perylene & N.D. & N.D. & N.D. & N.D. & N.D. & N.D. & N.D. & N.D. & N.D. & 6.73 & N.D. & 2.10 \\
\hline Indeno $(1,2,3-\mathrm{c}, \mathrm{d})$ pyrene & N.D. & N.D. & N.D. & N.D. & 0.15 & N.D. & N.D. & N.D. & N.D. & 3.07 & N.D. & 7.85 \\
\hline Total & 1.96 & 2.20 & 2.48 & 3.43 & 4.87 & 9.01 & 10.06 & 11.50 & 16.07 & 18.28 & 27.78 & 131.15 \\
\hline Total carcinogenic & 1.47 & 0.53 & 0.45 & 1.69 & 3.12 & 3.83 & 2.66 & 6.33 & 0.54 & 10.62 & 2.34 & 36.54 \\
\hline
\end{tabular}

The maximum levels of individual PAHs were recorded in dandelion: $30.79 \mu \mathrm{g} / \mathrm{kg}$ naphthalene, $28.91 \mu \mathrm{g} / \mathrm{kg}$ pyrene, $23.79 \mu \mathrm{g} / \mathrm{kg}$ phenanthrene and $10.28 \mu \mathrm{g} / \mathrm{kg}$ benzo(b)fluoranthene. Dandelion herbal tea exhibit also the largest PAH's range (14 PAHs).

The lowest PAHs concentrations were recorded in basil and fennel $(1.96$ and $2.20 \mu \mathrm{g} / \mathrm{kg})$, these being the least contaminated also in terms of PAH's range (only 7 from the studied PAHs).

Carcinogenic PAHs ranged from $0.45 \mu \mathrm{g} / \mathrm{kg}$ (lime) to $36.54 \mu \mathrm{g} / \mathrm{kg}$ (dandelion), with St.John's worth revealing the maximum concentration of benzo(g,h,i) perylene from all the samples.

Based on the obtained data, a PCA model was developed using 14 variables (PAHs'concentrations), in which: the first two principal components explain $76.33 \%$ variance (Figures 1 and 2), "mulberry" is an outlier, "dandelion" is outside the model border.

PCA revealed a close correlation between the recorded concentrations of naphtalene, anthracene, pyrene, benzo(a)pyrene, benzo(b)fluoranthene and benzo(k)fluoranthene (Figure 2). 


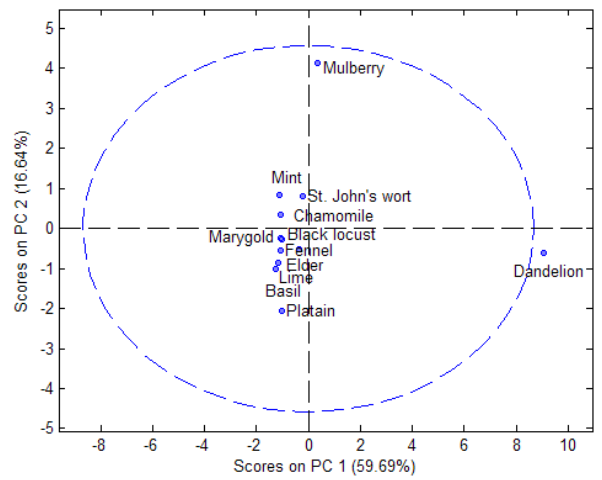

Figure 1. PCA scores.

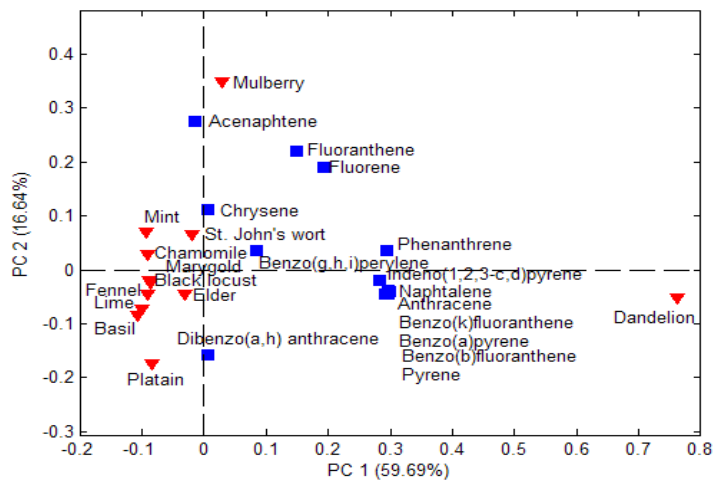

Figure 2. PCA biplot.

\section{Conclusions}

15 PAHs were determined in 12 herbal teas' brands, each product showing a particular contamination pattern

PAHs' contamination is more important for herba (dandelion, mulberry, St.John's wort) $>$ flos (common elder, black locust, lime) > semen (fennel) -with some exceptions.

The content of carcinogenic PAHs' are higher than 50\% from the total PAHs' content only for basil, black locust, marigold and St. John's wort.

The obtained data are comparable with the published ones [1-4], but showing much smaller PAHs' concentrations.

Author Contributions: E.M and N.M conceived and designed the experiments; N.M. performed the HPLC analyses; E.M analyzed the data; E.M and N.M. wrote the paper. All authors have read and agreed to the published version of the manuscript.

Conflicts of Interest: The authors declare no conflict of interest.

\section{Abbreviations}

The following abbreviations are used in this manuscript:

HPLC high performance liquid chromatography

PAH polycyclic aromatic hydrocarbons

PCA principal component analysis 


\section{References}

1. Benson, N.U.; Fred-Ahmadu, O.H.; Olugbuyiro, J.A.; Anake, W.U.; Adedapo, A.E.; Olajire, A.A. Concentrations, sources and risk characterisation of polycyclic aromatic hydrocarbons (PAHs) in green, herbal and black tea products in Nigeria. J. Food Compost. Anal. 2018, 66, 13-22, doi:10.1016/j.jfca.2017.11.003. Available online: https://reader.elsevier.com/reader/sd/pii/S0889157517302740?token=2F9E4C870838FA49791ED9081B248A 32B4F0C4BF68C44233D0FD6B7F7FD658C429D7ECC2C17C0A5C8756D0A2D8CFB0FE (accessed on 20 October 2020).

2. Ciecierska, M.; Obiedziński, M. The GC-MS analysis of polycyclic aromatic hydrocarbons content in selected fruit and herbal teas. Herba Pol. 2009, 55, 18-24. Available online: http://www.herbapolonica.pl/magazines-files/5781460-02.pdf (accessed on 15 October 2020).

3. Lin, D.; Tu, Y.; Zhu, L. Concentrations and health risk of polycyclic aromatic hydrocarbons in tea. Food Chem. Toxicol. 2005, 43, 41-48, doi:10.1016/j.fct.2004.08.010. Available online: https://www.sciencedirect.com/science/article/pii/S0308814613012156/pdfft?md5=715adda7f957495d1d75 17b9ce2cb68b\&pid=1-s2.0-S0308814613012156-main.pdf (accessed on 15 October 2020).

4. Zachara, A.; Gałkowska, D.; Juszczak, L. Contamination of tea and tea infusion with polycyclic aromatic hydrocarbons. Int. J. Environ. Res. Public Health 2018, 15, 45, doi:10.3390/ijerph15010045. Available online: https://www.mdpi.com/1660-4601/15/1/45/pdf (accessed on 20 October 2020).

Publisher's Note: MDPI stays neutral with regard to jurisdictional claims in published maps and institutional affiliations.

(C) 2020 by the authors. Submitted for possible open access publication under the terms and conditions of the Creative Commons Attribution (CC BY) license (http://creativecommons.org/licenses/by/4.0/). 